\title{
RESENHA: “FEMINIZAÇÃO DA POBREZA NO SENEGAL E A DINÂMICA DAS RELAÇÕES SOCIAIS NAS FAMÍLIAS: O CASO DO SUBÚRBIO DE DAKAR”
}

BOP, Codou. Feminização da pobreza no Senegal e a dinâmica das relações sociais nas famílias:: o caso do subúrbio operário de Dakar. Labrys: estudos feministas, [s. l.], n. 3, 2003.

Codou Bop ${ }^{1}$

\section{Dayane Teixeira ${ }^{2}$}

Feminização da pobreza no Senegal (2003), escrito pela socióloga e jornalista senegalesa Codou Bop, é fruto de uma comunicação apresentada pela mesma durante o Colloque International de la Recherche Feministe Francophone, ocorrido na França em setembro de 2002, e que foi traduzido e disponibilizado na plataforma da revista eletrônica Labrys- Estudos Feministas pela Prof. a Dra. Tania Navarro Swain.

Codou Bop também atua como coordenadora do Groupe de Recherche sur les Femmes e les lois no Senegal, e é membro do African Feminist Forum, um grupo fundado com o intuito de promover trocas e experiências a partir de uma perspectiva feminista africana. $\mathrm{O}$ texto traz à baila e problematiza um tema recorrente nas publicações da autora, e os dados apresentados partem de estudos que a mesma realizou nos anos 2000, como consultora do Ministério das Finanças, do Planejamento e do Ministério da Família, para abordar a realidade comungada pelas famílias residentes nos bairros periféricos de Dakar. Esse levantamento traz informações importantíssimas sobre a precarização do status social feminino. Dentre os fatores mencionados e que agravam a situação das mulheres nas zonas periféricas de Dakar, estão o desemprego - causado pelo fechamento de grande parte de usinas hortigranjeiras, uma das principais fontes de renda entre as famílias do entorno -, ausência da elaboração de políticas públicas específicas por parte de órgãos competentes, falta de apoio familiar - principalmente por parte dos maridos -, e a questão da poligamia - prática bastante comum em países de religião muçulmana, como o Senegal, por exemplo, onde aproximadamente 95\% da população é adepta ao Islã.

De acordo com o Alcorão, livro sagrado dos muçulmanos, o homem tem o direito de

1 BOP Codou. 2003. Feminização da pobreza no Senegal e a dinâmica das relações sociais nas famílias: o caso do subúrbio operário de Dakar. Revista Labrys - Estudos feministas N³.

2 Graduada em Letras pela Universidade Paulista, atua como pesquisadora independente com o foco em África, Africanidades e temas correlatos, sobretudo na área da Literatura (indígena e africana) e das Artes Visuais. Possui cursos de extensão e especialização em História da Arte, Literatura, Museologia e foi aluna do Centro de Estudos Africanos (CEA - USP). Email para contato: dayane dyn@hotmail.com 
desposar até quatro mulheres, desde que possa dar assistência total às esposas e aos filhos. Entretanto, quando os homens não respeitam essa regra e se esquivam de suas responsabilidades enquanto pai e marido, as famílias passam a fazer parte de um circuito de pobreza e marginalidade. Bop, pontua que a situação mais crítica está entre divorciadas e viúvas - estas se veem obrigadas a assumir o papel de gestoras e a custear despesas cotidianas, mesmo desempregadas ou dispondo de uma renda ínfima. As entrevistadas, inclusive, revelam que 8 em cada 10 famílias são sustentadas por mulheres, e que o poder de decisão dado aos homens, no contexto da união poligâmica - como o repúdio, por exemplo -, é uma das principais causas do abandono familiar.

Esse dado explica a perpetuação da pobreza feminina e, consequentemente, da comunidade, uma vez que, a relação entre desarrimo conjugal, baixa renda e a falta de infraestrutura, resulta na ausência de saúde, alimentação, educação e moradia digna para seus membros. Vale ressaltar que o analfabetismo entre as mulheres é um ponto delicado e extremamente preocupante, pois entre as comunidades, quando há a possibilidade de arcar minimamente com os estudos das crianças, a prioridade é dada aos meninos. Essa circunstância transforma-se num círculo vicioso e propagador do analfabetismo, impedindo reais perspectivas de avanço.

Para salientar o impacto que a prática poligâmica tem no Senegal, a socióloga apresenta um censo de 1998, onde 45,5\% da população está vinculada a esta modalidade matrimonial. Essa estatística endossa os depoimentos coletados durante as entrevistas e lança luz sobre o cotidiano das mulheres dakaroises ${ }^{3}$. Para contrapor a conjuntura de vulnerabilidade social feminina, Bop descreve as iniciativas e estratégias estabelecidas por grupos de mulheres, visando melhores condições de vida para si e para seus familiares.

O trabalho foi organizado em quatro tópicos e suas respectivas subdivisões. No primeiro tópico, Bop apresenta o contexto social do país; no segundo, fala sobre os três fenômenos essenciais que, de acordo com entrevistadas, ajudam a perpetuar a pobreza feminina. No terceiro tópico, apresenta as iniciativas que alguns grupos gerenciados por mulheres colocaram em prática a fim de brecar os efeitos da pobreza - o que inclui parcerias com ONGs, apoio da comunidade e a criação do Programa das Mulheres do Meio Urbano (PROFEMU), união de grupos femininos, iniciado com o intuito de conceder créditos e proporcionar maior autonomia financeira às suas afiliadas. $\mathrm{O}$ PROFEMU empreendeu, ainda, estratégias para combater o alto índice de analfabetismo e mirou no desenvolvimento pessoal de suas integrantes por meio da leitura e da escrita, bem como, na

3 Equivalente feminino de Dakarois; quem nasce em Dakar. 
capacitação dos grupos, abordando questões relacionadas à saúde, meio ambiente, planificação familiar etc.

Parágrafo deslocado... não sei se vi conexão com o parágrafo acima e abaixo. No quarto e último tópico, Bop analisa a evolução das relações de poder dentro da comunidade e no espaço doméstico, e, por fim, encerra o texto fazendo alguns apontamentos.

A partir das considerações feitas pela socióloga, nesta e em outras publicações sobre a condição da mulher, é possível observar que religião - neste caso, o islã -, é um fator amplamente debatido nos textos. É sabido que, durante séculos, a religião foi determinante na administração e aplicação de leis nas mais variadas esferas das sociedades.O que parece ser o caso do Islã, visto que, nos textos de autoria feminina, a lei islâmica está intimamente ligada à posição ocupada pelas mulheres na sociedade.

Ayaan Hirsi Ali, feminista, ativista e escritora somali, publicou livros baseados em sua experiência enquanto mulher e muçulmana; neles, questiona abertamente o Islã, propondo, inclusive, uma reforma em suas leis e na maneira como a comunidade as interpreta. Segundo ela, as atitudes desumanas, opressivas e violentas, encontram respaldo no Alcorão e, sobretudo, no Hadith - escritos baseados nas ações de vida do profeta Maomé. Desta forma, poligamia e mutilação genital feminina são veementemente rechaçadas por Ayaan. Entre os livros que escreveu e que foram publicados no Brasil, estão: Infiel (2007), Herege (2015), Nômade (2011) e A Virgem na Jaula (2008). Além de Ali, outras mulheres escreveram sobre o padrão poligâmico e seus desdobramentos. Podemos citar, por exemplo, Awa Thiam, Fatou Sow, Mariama Bâ e Fatou Diome - também senegalesas - e as escritoras Paulina Chiziane, de Moçambique e Buchi Emecheta, da Nigéria.

Os trabalhos publicados por estas autoras, sejam eles literários ou não, questionam a estrutura política estabelecida pela diretriz religiosa, que é determinante na vida das mulheres. Mesmo na literatura, as narrativas não são integralmente fictícias, pois abordam o universo da mulher africana a partir de suas experiências como tal. O ato de escrever é, portanto, uma ferramenta de denúncia e luta contra as opressões do patriarcado. Obras como So long a Letter (2008), Niketche: uma história de poligamia (2004), As alegrias da maternidade (2018) e Infiel (2007), são autobiográficas e nos permitem refletir sobre os efeitos que práticas como poligamia e abandono familiar têm na vida das mulheres. Os títulos mencionados dialogam e ratificam as 
declarações das entrevistadas, quando apontam a poligamia como um dos principais fenômenos que favorecem o quadro de vulnerabilidade social feminina.

Codou Bop, finaliza seu texto pontuando uma questão amplamente presente nas pautas feministas de todo o mundo, quando defende a urgência de pensarmos em ações que sensibilizem tanto os homens como as mulheres, visando descontruir o conceito de feminilidade e masculinidade, bem como, as atribuições que a sociedade dá a cada sexo. Não à toa, a feminista e escritora nigeriana, Chimamanda Ngozi Adichie, em seu célebre livro Para educar crianças feministas (2017), insiste que devemos traçar um caminho sem imposição de gênero e onde a educação é prioridade. Somente assim, podemos almejar uma sociedade mais justa e igualitária para todxs.

\section{REFERÊNCIAS:}

ADICHIE , Chimamanda Ngozi. Para educar crianças feministas: um manifesto. São Paulo: Companhia das Letras, 2017.

ALI, Ayaan Hirsi. Infiel. São Paulo: Companhia das Letras, 2007.

A virgem na jaula. São Paulo: Companhia das Letras, 2008.

.Nômade. São Paulo: Companhia das Letras, 2011.

.Herege. São Paulo: Companhia das Letras, 2015.

BÂ, Mariana. So long a letter. Inglaterra: Heinemann, 2018.

BOP, Codou. Feminização da pobreza no Senegal e a dinâmica das relações sociais nas famílias:: o caso do subúrbio operário de Dakar. Labrys: estudos feministas, [s. l.], n. 3, 2003.

BOP, Codou. Les femmes chefs de famille à Dakar. In: BISILLIAT, Jeanne et al. Femmes du Sud, chefs de famille. p. 130-149. Paris: Karthala, 1996.

BUCHI , Emecheta. As alegrias da maternidade. 2. ed. [S. l.]: Dublinense, 2018.

CHIZIANE, Paulina. Niketche: uma história de poligamia. São Paulo: Companhia das Letras, 2004.

THIAM, Awa. La parole aux négresses. França: Denoël-gonthier, 1979. 